\title{
The Calculating Model of Inventory Turnover Based on Time Value
}

\author{
Zhuo Qu \\ Dalian Yucai Shipping Company \\ Dalian Maritime University \\ Dalian 116026, China \\ quzhuo@dlmu.edu.cn
}

\author{
Bing Zhao \\ College of Management \\ Dalian Jiaotong University \\ Dalian 116028, China
}

\begin{abstract}
Inventory management level could represent a company's operating performance, and the rate of inventory turnover directly reflects the level of profits. Inventory being too high will make the enterprise be immersed in vicious spiral, and eventually lead to lower profits. Quick turnover rate can bring about many benefits for enterprises. So how to calculate the rate of inventory turnover becomes necessary. The traditional calculation method of inventory turnover rate was investigated firstly, and the existing problems were pointed out. A new model for calculating the rate of inventory turnover was established by introducing the time value theory of money. It is of reliable reference value for enterprises.
\end{abstract}

Keywords-inventory management; time value; inventory turnover rate

\section{INTRODUCTION}

As an important indicator of inventory management, the inventory turnover (ITO, in short) directly reflects the efficiency of inventory and cash flow of an enterprise. If the ITO is high, it means that the inventory management is good with a fast liquidating and great operating ability of enterprise. When it is low, the majority capital in an enterprise is backlog of inventory, which affects the liquidity and the yield of the enterprise [1]. So it is of important practical significance for an enterprise to improve inventory management level and promote accurate measure of the efficiency of inventory and cash flow via accurate calculation of ITO.

\section{TheORETICAL BASIS OF ITO}

\section{A. The Meaning of ITO}

ITO points to the number of times that inventory is sold and replaced (replenishment) in a certain period of time. It is equal to the cost of sales divided by average inventory [2], that is:

$$
\text { ITO }=\text { Cost of sales/Average inventory }
$$

Where average inventory is the inventory standard necessarily reserved in order to achieve certain sales (production), which is average inventory of raw materials, articles being produced, finished goods and all sluggish materials. It is the final average inventory in each financial cycle. Some companies take average inventory from the end of each quarter, while some others take it from the end of each month. It is the average of the initial inventory plus the final inventory in the calculation period [3] that is:
Average inventory $=($ Initial inventory + Final inventory $) / 2$

For example, if the sale cost of a company in the first quarter of 2015 is 6 million Yuan (Chinese currency unit, RMB), inventories are 1.2 million Yuan and 1.8 million Yuan respectively at the beginning and the end of the quarter, then the ITO $=600 /(120+180) / 2=4$ times. It is equivalent to the fact that the turnover of the enterprise is four times with average 1.5 million cash in a quarter, and the enterprise has earned profits four times either. So, if the quarterly average sale cost and average inventory is fixed, the enterprise's annual inventory turnover becomes $600 * 4 / 150=16$ times.

\section{B. Traditional ITO Calculation Model Analysis}

The ITO formula above, the traditional formula, is adopted by modern enterprises for calculating. Point inventories are used instead of inventory levels during the inventory period. If the inventory changes little in a statistic period, ITO obtained by using the traditional method can basically reflect the inventory and cash flow of the enterprise.

However, the traditional ITO formula cannot accurately reflect the efficiency of inventory and cash occupied, there are three reasons below:

Firstly, some inventories are not reliable at the points. A point of inventory cannot really reflect the daily cash need of the enterprise. The demand is fluctuating every day, because the customer's demand is volatile, especially in a fierce competition market. Along with the volatility of the market, inventory changes inevitably occur.

Secondly, it is easy to be controlled. When calculating the ITO from the points of the final and initial inventories, it is easy to make false in practice: artificially transfer inventory or control receiving of ERP system, such as excessive shipment in the end of the month, rejection of replenishing stock until the following month early, etc. [5].

Finally, there exists the hump phenomenon. "Hump phenomenon" of inventory usually can appear in the enterprise practice, that is maintaining low prices or even almost zero inventory at the beginning and the end of the computing cycle, while special high inventory is kept during the period. For example, the production cycle of an enterprise is only one day and there is no order from the customer at the end of this month. If we can do the JIT (Just-in-time), that is to say timely 
delivery of the goods, the final inventory will remain very low or even zero, and also do the same at the beginning. According to the traditional formula to calculate, the inventory turnover will be particularly large or trend to be infinity as the denominator of the calculating formula almost approaches zero. So it means that the enterprise inventory cycle is zero, namely there is no need of cash for operating enterprise. But this is impossible. Fig. 1 below shows this kind of situation.

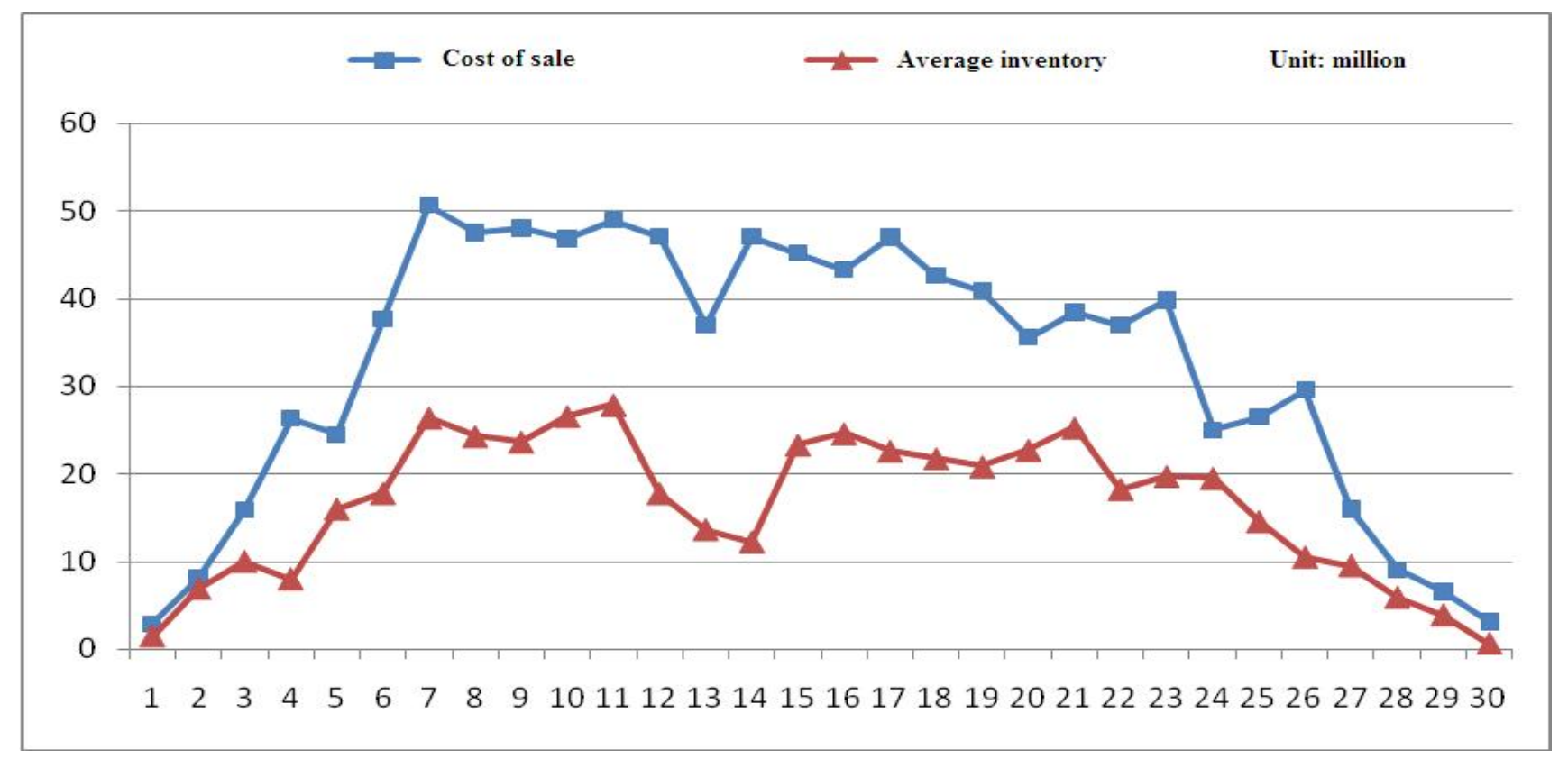

Fig. 1. Business inventories of hump phenomenon

\section{The CAlCUlating MODEL OF INVENTORY TURNOVER BASED ON THE TIME VALUE}

\section{A. Problem}

As each month the inbound and outbound of goods take place in different date, so the goods time in stock is different. Take 30 days a month for example. Two batches of goods are put in storage on $3^{\text {rd }}$ day and $13^{\text {th }}$ day respectively. In the case of no outbound, goods put in storage in $3^{\text {rd }}$ day will stay 27 days in stock, and warehousing goods from $13^{\text {th }}$ day is only last 17 days. And different time of inbound and outbound will directly affect the time of the goods taking up money. Since money has time value, in order to accurately calculate the inventory turnover rate which reflects the real situation in an enterprise, the influence of time value should be took into consideration. Next, calculation model of inventory turnover with considering the time value of money will be proposed.

\section{B. Calculation Model}

The computation period of the inventory turnover ratio is different for different enterprises [4]. Some use year cycle as a period, others adopt quarterly or monthly cycle. Here month cycle is utilized as inventory turnover calculation period.

Let $\mathrm{n}$ be the number of days for the month. The concrete symbol and formulae are as follows:

1) stock ( $i)$ is the stock at the i-th day of the computing cycle, $0 \leq i \leq n$.
2) $\operatorname{stock}(0)$ is the stock at the beginning of the computing cycle.

3) sale (i) is the cost of sale at the i-th day of the computing cycle.

4)

$$
S_{n}=\operatorname{stock}(n)-\operatorname{stock}(n-1)
$$

5)

Average Stock $=$ Stock $(0)+\sum_{i=1}^{n}\left(S_{n} * \frac{n+1-i}{n}\right)$

So

$$
\text { ITO }=\frac{\sum_{i=1}^{n} \operatorname{sale}(i)}{\text { Average Stock }}
$$

where ITO is the ratio of cost of sale and average inventory.

Nowadays, most of the enterprises have their own set of management systems (such as ERP), which can be extracted random inventory data. It is easy to get the inventory change 
value every day, which provides a guarantee for the accurate calculation of ITO. In this calculation model, if increased by 3.7717 million the first day, the 3.7717 million is believed to exist in the whole month (30 days). The 2nd and 3rd day respectively increase by 8.2092 million and 9.7061 million. That is to say that the goods increased in those two days exists in 29 and 28 days respectively. Moreover, if the goods in the 4th day decreased by 576600, it is considered without these goods in the remaining 27 days, but it still exists in first three days, so the calculation result is minus $576600 *(27 / 30)$. The rest of the days will be calculated in the same way.

\section{Application and Analysis}

The ITO of Dalian IKEA Store by the cost of sale and inventory data in June 2012 will be analyzed. The enterprise daily inventory cost of sale is shown in TABLE I .

TABLE I. DALIAN IKEA STORE’s SALE COST AND PREDEFINED IN JUNE 2012 (UNIT: MILLION)

\begin{tabular}{|c|c|c|c|c|c|}
\hline date & sale(i) & stock(i) & date & sale(i) & stock(i) \\
\hline 1 & 97.02 & 2897.36 & 16 & 61.19 & 4824.8 \\
\hline 2 & 47.96 & 3718.28 & 17 & 63.39 & 4696.56 \\
\hline 3 & 59.95 & 4688.89 & 18 & 74.93 & 4661.58 \\
\hline 4 & 50.19 & 4631.23 & 19 & 82.49 & 4586.45 \\
\hline 5 & 100.86 & 4647.01 & 20 & 71.25 & 4553.91 \\
\hline 6 & 78.31 & 4764.56 & 21 & 129.17 & 4439.6 \\
\hline 7 & 141.67 & 4758.64 & 22 & 124.09 & 4493.91 \\
\hline 8 & 129.15 & 4749.91 & 23 & 72.64 & 4477.53 \\
\hline 9 & 67.06 & 4799.32 & 24 & 50.93 & 4401.86 \\
\hline 10 & 59.05 & 4680.34 & 25 & 54.88 & 4351.63 \\
\hline 11 & 90.03 & 4690.41 & 26 & 49.04 & 4257.55 \\
\hline 12 & 74.82 & 4701.99 & 27 & 52.18 & 4301.1 \\
\hline 13 & 62.67 & 4693.87 & 28 & 90.13 & 4307.13 \\
\hline 14 & 122.62 & 4705.12 & 29 & 88.15 & 3862.27 \\
\hline 15 & 130.38 & 4815.31 & 30 & 61.1 & 3320.37 \\
\hline $\begin{array}{l}\text { Selling cost } \\
\text { summation }\end{array}$ & \multicolumn{2}{|c|}{2437.3} & $\begin{array}{c}\text { Opening } \\
\text { inventory }\end{array}$ & \multicolumn{2}{|c|}{2520.19} \\
\hline
\end{tabular}

According to the traditional formula, the enterprise inventory turnover ratio is:

$$
\text { ITO }_{1}=\frac{2437.3}{(2897.36+3320.37) / 2} \times 12=9.41
$$

Using the calculation model proposed here, the enterprise's inventory turnover ratio is:

$$
S_{0}=2520.19
$$

\section{ITO}

$$
\begin{aligned}
& =\frac{\sum_{i=1}^{n} \operatorname{sale}(i)}{\text { Average Stock }} \\
= & \frac{2437.3 \times 12}{2520.19+\frac{377.17 \times 30}{30}+\cdots-\frac{541.9 \times 1}{30}} \\
= & 6.57
\end{aligned}
$$

The calculation results of the traditional method and the method are shown in TABLE II. TABLE II shows that using traditional formula to calculate, the ITO is 9.41 and DOS is 39 days. Thus it may be calculated that the average daily fund enterprise taken is 31.6849 million Yuan, but the reality is that we need around 45 million cash every day, significantly higher than the calculated 31.6849 million Yuan. It shows that ITO is difficult to accurately reflect the actual operation of the enterprise in the traditional method calculated. Thus it can't provide reliable decision-making information to management, and is likely to mislead decision-making and brings loss to the enterprise. And using this ITO calculated model we can derive the occupied capital of 45.4962 million Yuan a day on average, which is very close to 45 million, the actual cash demand for the enterprise operation. This shows that the proposed ITO calculation model has certain rationality, and can accurately reflect the enterprise's actual situation.

\section{The proposed method has the following property:}

On the one hand, the model considers the influence of time in the inventory. As the aim of enterprise inventory control is to keep funds that the inventory tied up in a reasonable range, in order that accommodation of money could be better, the time of the funds occupied must be shorten The time impact on inventory occupied capital for this model is took into account.

On the other hand, it could avoid human operation. When using ITO traditional formula, it is easy to make false in practice: artificially transfer inventory or control receiving of ERP system, such as excessive shipment in the end of the month, rejection of replenishing stock until the following month early, etc. ITO proposed in this paper, the calculation model, can largely eliminate the impact of these unreasonable behaviors. If they hurriedly shipped 5 million, then the stock of 30th day turns into 2820.27, then calculated ITO is 6.59. The difference between it and the original calculation ITO is not big, so the method can reduce the enterprise's relevant personnel the driving force of advanced shipment deliberately in the end of the month. To a certain extent, it avoids the result due to the imperfect internal control that the sale department does credit sale of goods for customer picking up the goods in advance. As result eventually the receivables do not come back. Furthermore, if the relevant personnel weights the next month 
more as a reduction, the backlog of goods at the beginning of the next month will directly cause the following month early full weight of inventories and self-defeating.

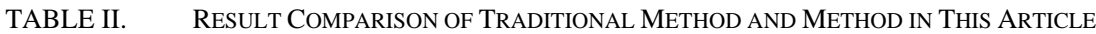

\begin{tabular}{|c||c|c|c|}
\hline \hline & ITO & $\begin{array}{c}\text { Days Of Store } \\
\text { (DOS)(365/ITO) }\end{array}$ & $\begin{array}{c}\text { Average occupation of } \\
\text { capital each day(selling } \\
\text { cost/30*DOS) }\end{array}$ \\
\hline \hline Traditional method & 9.41 & 39 & 3168.49 \\
\hline \hline Method in this article & 6.57 & 56 & 4549.62 \\
\hline
\end{tabular}

\section{CONCLUSION}

High turnover value does not represent high profits. High profits comes from the effective inventory control and return on investment (ROI), which means the higher ITO the higher return on investment. Therefore only accurate calculation of ITO can reflect the enterprise's capital operation situation.

\section{REFERENCES}

[1] Liu An, Yu Qing, Liu Xiaolong, He Lin, Yang Jing. "Management practice and study of improving inventory turnover ratio," Hebei Enterprises, no. 1, vol. 4, pp. 9-11, 2011. (In Chinese)

[2] Wang Jianqi. "Application of stock rate of turnover in coating business enterprise,” Journal of Chemical Industry in Guangzhou, no. 6, vol. 34, pp. 69-71, 2006. (In Chinese)
Calculation model of ITO based on the time value can accurately calculate the actual value of enterprise capital and inventory turnover, and improve the level of inventory management. The calculation model of ITO put forward can provide reference for strengthening enterprise inventory control.

[3] Ren Li. "Inventory turnover ratio analysis of Clothing enterprise," Reform and Management, no. 3, vol. 4, pp. 5-7, 2009. (In Chinese)

[4] Liang Xiangang, Gong Yingcai, Li Mengjun, Wang Enxian. "Optimizing the inventory structure and improving the rate of inventory turnover,” China Medical Equipment, no. 1, vol. 7, pp. 23-25, 2010. (In Chinese)

[5] Xie Wuzhou, Guo Chengheng. "Index analysis and evaluation of logistics enterprise inventory turnover ratio,” Modern Logistics, no. 3, vol. 5, pp. 66-67, 2007. (In Chinese) 